\title{
Pile lateral subgrade reaction modulus for Jakarta
}

\author{
Saskia Nadilla ${ }^{1, *}$ and Widjojo Adi Prakoso ${ }^{2}$ \\ ${ }^{1}$ Department of Civil Engineering, Faculty of Engineering, Universitas Indonesia, Depok, Indonesia
}

\begin{abstract}
The behavior of laterally loaded piles could be simulated by the subgrade reaction model. The primary soil parameter for this model is the subgrade reaction modulus, and in this paper, the correlation between the subgrade reaction modulus and the soil N-SPT value is examined by conducting numerical analyses of 34 pile cyclic lateral load tests in Jakarta. In each analysis, the pile is modeled as a series of beam elements, while the surrounding soil is modeled as a series of linear elastic springs. The moduli are varied according to the N-SPT values recorded in the associated deep boring data. In each load cycle, a trial and error process is conducted to match the resulting pile head lateral deflection to the measured value. The resulting correlation between the subgrade reaction modulus and the pile lateral deflection is presented for the 34 case studies and compared to a correlation in the literature. Furthermore, the analyses reveal that subgrade reaction modulus is affected by the magnitude of measured deflection, by the applied lateral loads, as well as by the construction methods.
\end{abstract}

\section{Introduction}

Foundations are designed to transfer loads from the upperstructures to soil, and therefore their stability and serviceability have to be ensured. One of the design checks is the lateral deflection of a pile, as the pile may be subjected to lateral forces and moments. The allowable lateral resistance is typically governed by the allowable lateral deflection, and the lateral resistance could be determined by performing relevant analyses and conduction field load tests.

One of the methods to analyse pile lateral deflection is the subgrade reaction method. In this method, the soil surrounding the pile is represented by a series of springs having certain lateral subgrade reaction modulus $(\mathrm{kh})$, and the soil deformation at any depth is affected by the corresponding soil reaction. The most common field soil test is the standard penetration tests (SPTs), and therefore the subgrade reaction modulus could be correlated to the output of the SPTs. The aim of this research is to develop the correlation between soil lateral subgrade reaction modulus $\left(\mathrm{k}_{\mathrm{h}}\right)$ and N-SPT values. The development is based on a series of cyclic lateral load test results. The resulting correlation is then discussed relative to similar correlations available in the literature.

\section{Literature review}

\subsection{Pile foundation}

Piles may be classified according to their composition as timber piles, concrete piles, and steel piles. According to the method of construction, there are three types of piles: driven piles, cast-in-situ piles, driven and cast-in-situ piles. When the piles are concrete, they are to be precast. They may be driven either vertically or at an angle to the vertical [1].

\subsection{Pile lateral loading test}

Lateral loading test on single pile or group piles is performed based on ASTM Designation D 3966-60. The purpose of lateral loading test on pile is to determine pile lateral capacity, lateral deflection, and the response of soil-pile system to lateral loads and may provide data for engineering design and quality control.

There are some requirements and procedures for lateral testing of single pile or group piles. The test area within a radius of $20 \mathrm{ft}(6 \mathrm{~m})$ from the test pile or group shall be excavated or filled to the final grade elevation before testing the pile or pile group. Lateral test loads shall be applied at approximately pile cut-off elevation. For lateral loads testing of pile groups, except batter pile frames, the group of piles shall be capped with a reinforced concrete cap. Bearing plates used in the test shall be of steel and of sufficient size to accommodate spherical bearings, load cells, hydraulic jacks, and struts, and to transmit the applied lateral loads without detrimental high unit pressures. Bearing plates shall be of adequate thickness to prevent bending under the applied load but shall not be less than $50 \mathrm{~mm}$ thick [2].

\footnotetext{
Corresponding author: saskianadilla97@gmail.com
} 
The maximum lateral load applied on testing is $200 \%$ of the proposed lateral design load of the single pile or pile group. Loading procedures of the test is differentiated as standard loading, loading in excess of standard test load, cyclic loading, surge loading, reverse loading, reciprocal loading, loading to specified total lateral movement, and combined loading.

Table 1. Standard loading procedures.

\begin{tabular}{|c|c|c|c|}
\hline $\begin{array}{c}\text { Percentage } \\
\text { of Design } \\
\text { Load (\%) }\end{array}$ & $\begin{array}{c}\text { Load } \\
\text { Duration } \\
\text { (minute) }\end{array}$ & $\begin{array}{c}\text { Percentage } \\
\text { of Design } \\
\text { Load (\%) }\end{array}$ & $\begin{array}{c}\text { Load } \\
\text { Duration } \\
\text { (minute) }\end{array}$ \\
\hline 0 & 10 & 75 & 10 \\
\hline 25 & 10 & 0 & 10 \\
\hline 50 & 10 & 50 & 10 \\
\hline 25 & 10 & 100 & 10 \\
\hline 0 & 10 & 150 & 10 \\
\hline 50 & 10 & 170 & 20 \\
\hline 75 & 15 & 180 & 20 \\
\hline 100 & 20 & 190 & 20 \\
\hline 50 & 10 & 200 & 60 \\
\hline 0 & 10 & 150 & 10 \\
\hline 50 & 10 & 100 & 10 \\
\hline 100 & 10 & 50 & 10 \\
\hline 125 & 20 & 0 & $\ldots$ \\
\hline 150 & 20 & & \\
\hline
\end{tabular}

\subsection{Lateral loading on pile}

Lateral loading analysis on pile is developed from Finite Difference Method (FDM) by Howe (1955), MatlockReese (1960) and Bowles (1968). Matlock and Reese (1956) used FDM to develop non-dimensional curve to calculate maximum deflection and bending moment at pile head. Non-dimensional curve then developed with various soil moduli. The analysis of laterally loaded single piles are based on some assumptions: the laterally loaded pile behaves as an elastic member and the supporting soil behaves as an ideal elastic material, the theory of subgrade reaction is applicable, and there is no axial load [1]. If the assumption of linear behaviour is introduced for the pile, and if deflections remain small relative to the pile dimensions, the principle of superposition may be employed [3].

One of the method in analysing the behaviour of pile on lateral loading is p-y method. The p-y method models the foundation using two-dimensional finite difference analysis. It divides the foundation into $n$ intervals with a node at the end of each interval, and the soil as a series of nonlinear "springs" located at each node. The flexural rigidity of each interval is defined by the appropriate EI, and the load-deformation properties of each spring is defined by a $p-y$ curve. The curve expressed in the form of $p-y$ curves, where $p$ is the lateral soil resistance per unit length of the foundation and $y$ is the lateral deflection. The $p$-y curve for a particular point on a foundation depends on many factors, including soil type, type of loading, foundation diameter and cross-sectional shape, coefficient of friction between foundation and soil, depth below the ground surface, foundation construction methods, and group interaction effects [1].

\subsection{Subgrade reaction modulus}

The modulus of subgrade reaction is a conceptual relationship between soil pressure and deflection that is widely used in the structural analysis of foundation members. Basic equation of subgrade reaction modulus is [5]:

$$
\boldsymbol{k}_{s}=\frac{q}{\delta}
$$

$\mathrm{q}$ is known as soil reaction per unit length and $\delta$ as pile deflection. The coefficient $k s$ units in force per length cube. Plots of q versus $\delta$ from load tests give curves of the type qualitatively shown in Fig. 1 as bellow:

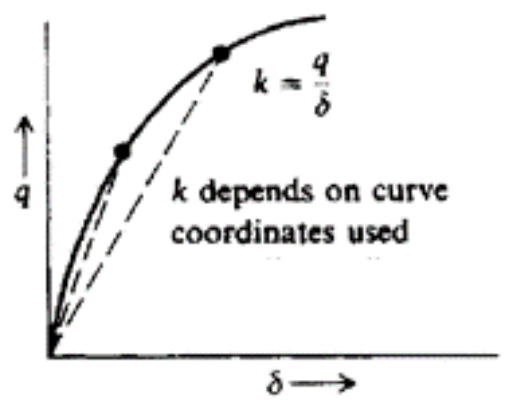

Fig. 1. Determination of Subgrade Reaction Modulus

There are many factors that have an influence on the value of subgrade reaction modulus. The most important factors are pile width or diameter, soil properties, nature and magnitude of loading, the flexural stiffness EI of the pile material. It is well-known quantitively that subgrade reaction modulus varies with soil properties [1].

\section{Research method}

\subsection{Loading test data}

The load test data used in this research consists of eleven (11) data sets from laterally loaded $0.45 \mathrm{~m}$ and $0.50 \mathrm{~m}$ in diameter driven piles, three (3) data sets from laterally loaded $1.0 \mathrm{~m}$ and $1.2 \mathrm{~m}$ in diameter driven piles, and twenty (20) data sets from laterally loaded $0.8 \mathrm{~m}$ to $1.2 \mathrm{~m}$ in diameter bored piles. The first group is taken from three (3) project locations, while the second group is taken from a project location. The bored pile data sets were taken from seven (7) project locations. In each project location, a series of borings containing N-SPT values were available. All locations are in Jakarta.

The lateral load tests were performed based on ASTM D 3966-07 (ASTM 2007). The maximum lateral load applied during tests was $200 \%$ of the design lateral design resistance. Each load test was conducted as follows: cycle I: $50 \%$ of design resistance, cycle II: $100 \%$ of design resistance, cycle III: $150 \%$ of design resistance, and cycle IV: $200 \%$ of design resistance. The test condition is free-head condition, and lateral test load was applied at approximately cut-off elevation. The lateral deflection was measured at the elevation as the applied load. It is noted that all test results show non-linear lateral load - lateral deflection behaviour. 


\subsection{Numerical model}

In this paper, a laterally loaded pile is numerically modelled as a series of $1.0 \mathrm{~m}$ long elastic beam elements, while the surrounding soil is represented as a series of elastic springs perpendicular to the beam at the $1.0 \mathrm{~m}$ interval nodes. As the test condition was free-head, no structural lateral supports were provided for the beam model. The conceptual model is shown as Fig. 2.

The stiffness of elastic springs or the subgrade reaction modulus varied with depth, in accordance to the actual N-SPT value distribution with depth reported in the soil investigation reports. It is highlighted that the actual lateral load - lateral deflection behaviour was non-linear, while that the spring model is linear elastic. To bridge this different fundamental behaviour, the subgrade reaction modulus would be determined for each load cycle, with a total of four (4) load cycles for each pile. As suggested by Fig. 1, the modulus would decrease with an increase in applied lateral load.

The correlation between subgrade reaction modulus $k_{h}$ (in unit of $\mathrm{MN} / \mathrm{m}^{3}$ ) and N-SPT is shown as follows:

$$
k_{h}=x \cdot N_{S P T}
$$

Equation (2) shows that the correlation between $k_{h}$ and $\mathrm{N}-\mathrm{SPT}$ is assumed to be linear. In each load cycle, a trial and error process to define for the $x$ coefficient is conducted to match the resulting pile head lateral deflection to the measured value. The tolerated error in the trial and error process is $0.0005 \%$.

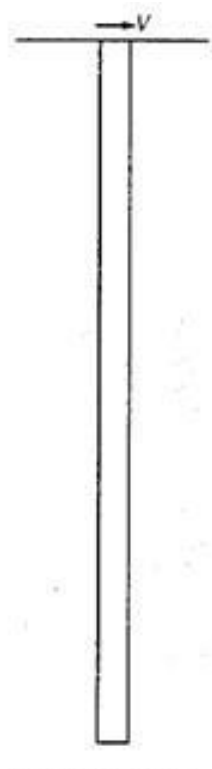

Actual Foundation

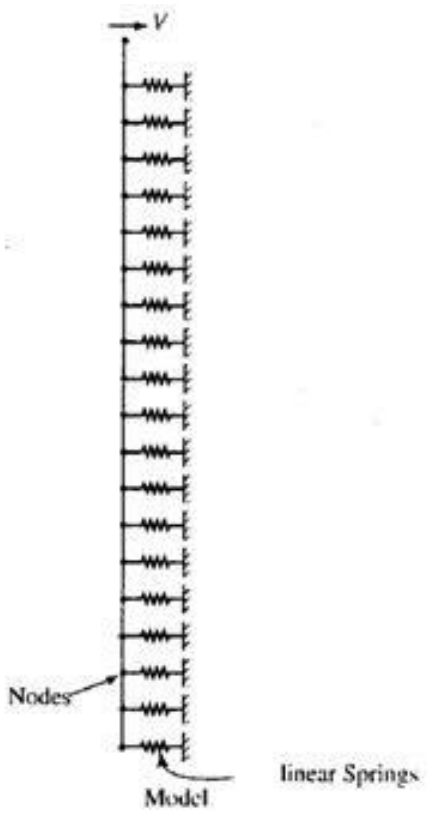

\section{Result and analysis}

The value of $x$ coefficient for each cyclic loading of bored and driven piles analysed in this study is shown in the table 2.

\subsection{Driven piles: $\mathbf{4 3 0} \mathrm{mm}$ and $500 \mathrm{~mm}$}

Figure 3 shows the four-cycle results for eleven (11) 0.45 $\mathrm{m}$ and $0.50 \mathrm{~m}$ in diameter driven piles from three (3) project locations. Some details are provided in Table 2. It can be seen that the correlation tends to decrease as the lateral deflection increases. The result of regression analysis is shown on the figure 3 , and the $\mathrm{R}^{2}$ value is 0.76 indicating relatively good correlation. The correlation average and minimum values for lateral deflection $10 \mathrm{~mm} \pm 1 \mathrm{~mm}$ is 10.16 and 7.19 , respectively, while the regression analysis given the correlation value of 11.82 . The overall minimum value is 4.76 for a pile lateral deflection of $20 \mathrm{~mm}$.

\subsection{Pre-bored driven piles: $1.0 \mathrm{~m}$ and $1.2 \mathrm{~m}$}

Figure 4 shows the four-cycle results for three (3) $1.0 \mathrm{~m}$ and $1.2 \mathrm{~m}$ in diameter pre-bored driven piles from one (1) project location. Some details are provided in Table 2. It can be seen that the correlation tends to decrease as the lateral deflection increases. The result of regression analysis is shown on the figure 4 , and the $\mathrm{R}^{2}$ value is 0.89 indicating relatively good correlation. The correlation average and minimum values for lateral deflection $10 \mathrm{~mm} \pm 1 \mathrm{~mm}$ is 1.62 and 1.48 , respectively, while the regression analysis given the correlation value of 1.68 . The overall minimum value is 0.82 for a pile lateral deflection of about $21 \mathrm{~mm}$.

\subsection{Bored piles: $1.0 \mathrm{~m}-1.2 \mathrm{~m}$}

Figure 5 shows the four-cycle results for twenty (20) 0.8 $\mathrm{m}$ to $1.2 \mathrm{~m}$ in diameter bored piles from seven (7) project locations. Some details are provided in Table 2. It can be seen that the correlation tends to decrease as the lateral deflection increases. The result of regression analysis is shown on the figure 5 , and the $\mathrm{R}^{2}$ value is 0.70 indicating relatively good correlation. The correlation average and minimum values for lateral deflection 10 $\mathrm{mm} \pm 1 \mathrm{~mm}$ is 3.73 and 2.39 , respectively, while the regression analysis given the correlation value of 3.28. The overall minimum value is 0.93 for a pile lateral deflection of about $23 \mathrm{~mm}$.

Fig. 2. Numerical Model of Laterally Loaded Piles

Table 2. Coefficient value of each cyclic loading

\begin{tabular}{|c|c|c|c|c|c|c|}
\hline \multirow{2}{*}{ Type of Pile } & \multirow{2}{*}{ Pile } & \multirow{2}{*}{$\begin{array}{c}\text { Diameter } \\
(\mathbf{m m})\end{array}$} & & \multicolumn{4}{|c|}{ Coefficient (MN/m $\mathbf{m}^{\mathbf{3}}$ ) } \\
\cline { 4 - 7 } & & & Cycle I & Cycle II & Cycle III & Cycle IV \\
\hline Bored & WA - BP. 154 & 1000 & 15.97 & 7.81 & 6.25 & 4.05 \\
\hline
\end{tabular}




\begin{tabular}{|c|c|c|c|c|c|c|}
\hline \multirow{2}{*}{ Type of Pile } & \multirow{2}{*}{ Pile } & \multirow{2}{*}{$\begin{array}{c}\text { Diameter } \\
(\mathbf{m m})\end{array}$} & \multicolumn{4}{|c|}{ Coefficient $\left(\mathrm{MN} / \mathrm{m}^{3}\right)$} \\
\hline & & & Cycle I & Cycle II & Cycle III & Cycle IV \\
\hline Bored & WA - BP. 198 & 800 & 48.46 & 36.25 & 24.61 & 17.92 \\
\hline Bored & WA - BP. 338 & 800 & 16.42 & 7.70 & 4.42 & 1.17 \\
\hline Bored & WA - BP. 130 & 1000 & 28.25 & 17.66 & 14.25 & 9.25 \\
\hline Bored & WA-BP. 6.051 & 1000 & 5.68 & 4.70 & 3.55 & 2.43 \\
\hline Bored & WA-BP. 6.135 & 1000 & 16.73 & 11.91 & 9.19 & 3.49 \\
\hline Bored & WA-BP. 5.55 & 1000 & 7.95 & 5.28 & 3.54 & 2.39 \\
\hline Bored & WA - BP. 5.262 & 1000 & 49.72 & 13.11 & 11.32 & 8.00 \\
\hline Bored & WA-BP. 7.164 & 1000 & 36.16 & 45.45 & 17.33 & 4.95 \\
\hline Bored & WA - BP.7.082 & 1000 & 30.15 & 16.85 & 11.20 & 4.43 \\
\hline Bored & WA-BP. 4.117 & 1000 & 27.10 & 16.66 & 14.17 & 9.75 \\
\hline Bored & WA - BP. 3.160 & 1000 & 23.95 & 11.78 & 6.86 & 3.75 \\
\hline Bored & Her. - BP. 71 & 1000 & 24.48 & 6.17 & 2.73 & 2.14 \\
\hline Bored & Her. - BP.42 & 1200 & 8.46 & 4.21 & 1.62 & 0.93 \\
\hline Bored & RNIO - BP. 98 RNI & 1000 & 16.00 & 5.71 & 4.66 & 3.78 \\
\hline Bored & $\mathrm{OcO}-\mathrm{VL} .1$ & 1000 & 13.76 & 6.70 & 4.86 & - \\
\hline Driven & $\mathrm{PDH}-\mathrm{H}-1 / 6$ & 450 & 33.78 & 21.12 & 13.09 & 7.19 \\
\hline Bored & $\mathrm{GH}-\mathrm{BP} .51$ & 800 & 94.34 & 3.56 & 3.23 & 2.56 \\
\hline Driven & $\mathrm{SPC}-783$ & 500 & 51.02 & 42.10 & 29.00 & 14.29 \\
\hline Driven & TA - TP. 210 & 450 & 111.25 & 70.41 & 55.56 & 12.55 \\
\hline Driven & TA - TP.193 & 450 & 12.59 & 12.78 & 11.83 & 7.95 \\
\hline Driven & TA - TP.350 & 450 & 49.38 & 14.19 & 8.13 & - \\
\hline Bored & BHMKG - BP.20 & 800 & 7.15 & 8.46 & 5.54 & 2.82 \\
\hline Bored & MO - TP.5 & 800 & 12.85 & 8.82 & 7.64 & 4.26 \\
\hline Bored & $\mathrm{MO}-\mathrm{TP} .64$ & 800 & 79.78 & 23.55 & 25.33 & 19.96 \\
\hline Driven & $\mathrm{SPC}-27 \mathrm{~S}$ & 500 & 107.99 & 59.60 & 49.95 & 28.30 \\
\hline Driven & SPC - 98S TP.3 & 500 & 30.59 & 19.59 & 12.60 & 8.40 \\
\hline Driven & SPC $-.98 \mathrm{~S}$ TP.4 & 500 & 24.41 & 13.96 & 9.10 & 4.77 \\
\hline Driven & $\mathrm{SPC}-126$ & 500 & 53.81 & 36.07 & 26.54 & 19.44 \\
\hline Driven & $\mathrm{SPC}-.556$ & 500 & 107.99 & 45.77 & 32.30 & 15.50 \\
\hline Driven & SPC -708 & 500 & 62.04 & 32.82 & 20.98 & 13.98 \\
\hline Driven & LRTJ - 239 & 1200 & 4.69 & 2.49 & 2.71 & 2.11 \\
\hline Driven & LRTJ - 339 & 1000 & 3.91 & 2.81 & 2.42 & 1.77 \\
\hline Driven & LRTJ - 380 & 1200 & 5.23 & 2.67 & 1.24 & 0.69 \\
\hline
\end{tabular}

\subsection{Discussions}

The correlation for $0.45 \mathrm{~m}$ and $0.50 \mathrm{~m}$ in diameter driven piles appear to be the highest, followed by that for 0.8 $\mathrm{m}-1.2 \mathrm{~m}$ in diameter bored piles and that for $1.0 \mathrm{~m}$ and
$1.2 \mathrm{~m}$ in diameter pre-bored driven piles. All these indicate the influence of construction methods on the correlations. However, for pre-bored driven piles and bored piles with comparable diameters at relatively large lateral deflection, the correlation is about the same. 
These correlations tend to greater than those in the literature. For example, OCDI (2002) shows the median value of similar correlation of 2.0 for driven piles. This correlation would provide a relatively conservative design for allowable lateral pile resistance.

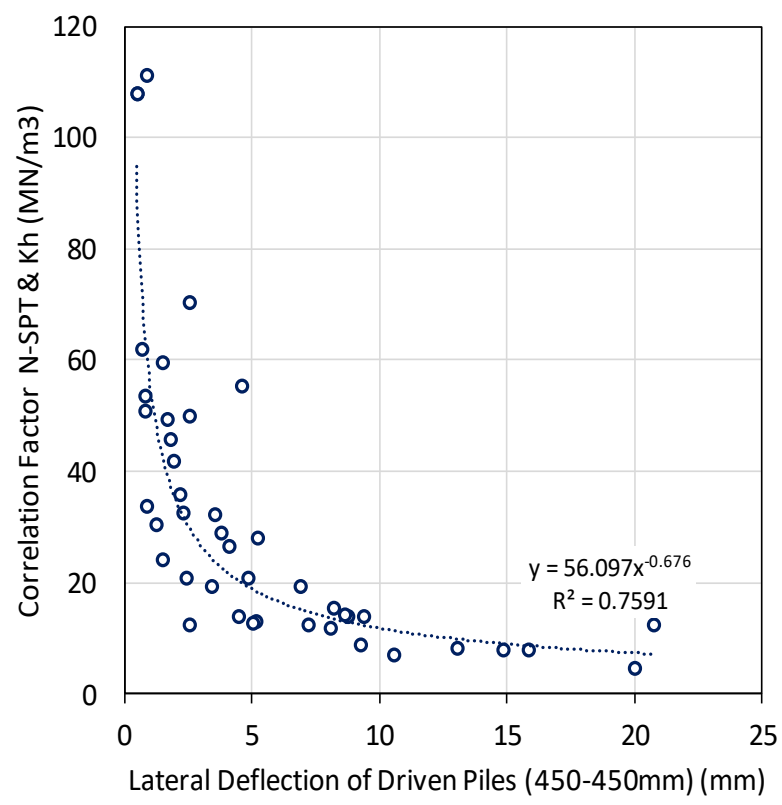

Fig. 3. Correlation between Coefficient Factor and Calculated Lateral Deflection for Driven Piles

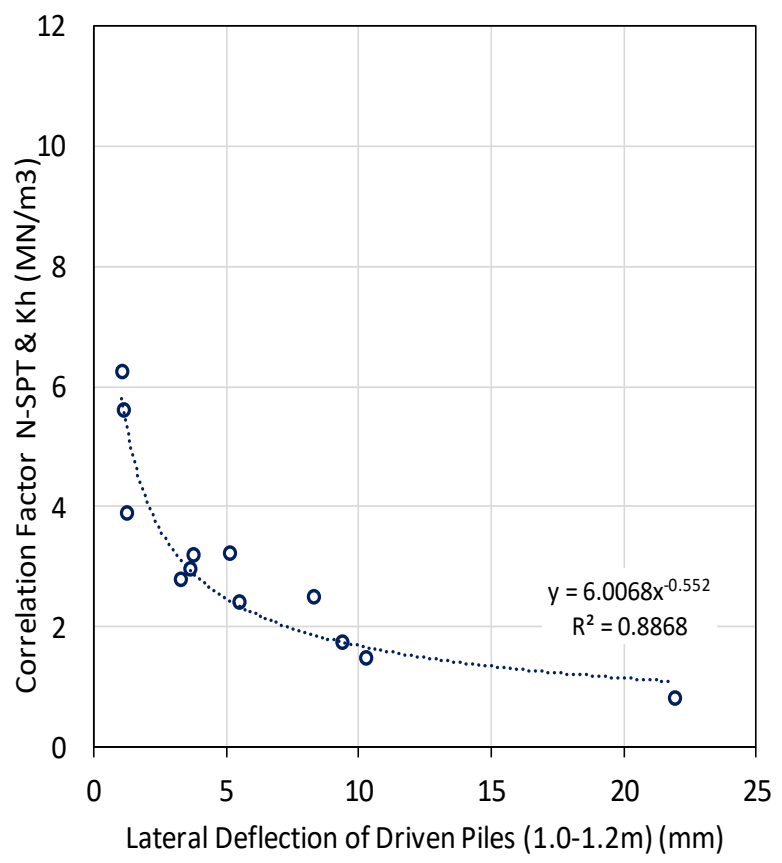

Fig. 4. Correlation between Coefficient Factor and Calculated Lateral Deflection for Large Diameter Pre-bored Driven Piles

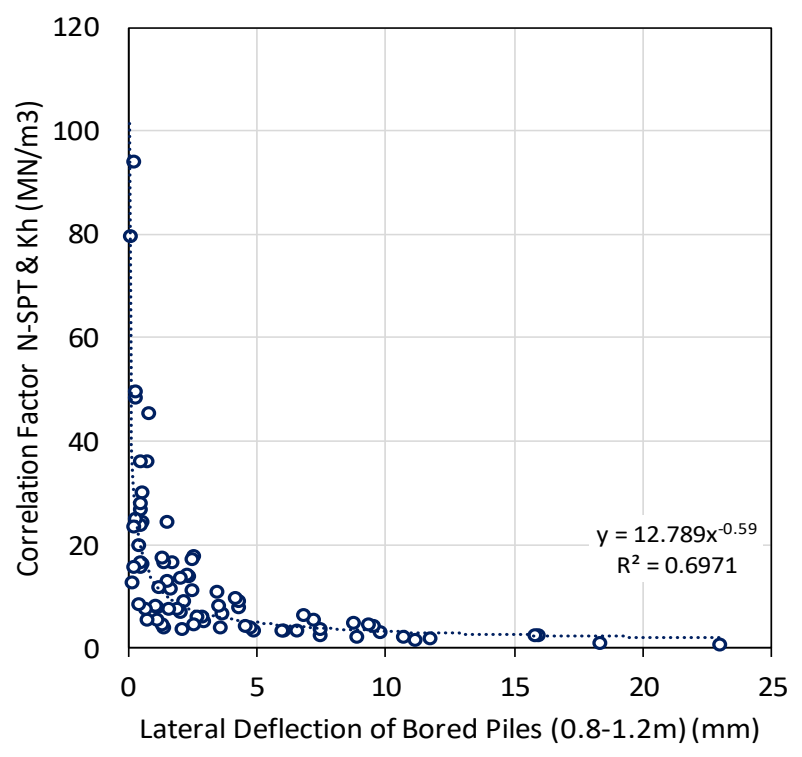

Fig. 5. Correlation between Coefficient Factor and Calculated Lateral Deflection for Large Diameter Bored Piles

\section{Conclusions}

The behaviour of laterally loaded piles could be simulated by subgrade reaction model. In this paper, the soil N-SPT value was examined by conducting numerical analyses of 34 pile cyclic lateral load tests in Jakarta. Eleven $0.45 \mathrm{~m}$ and $0.50 \mathrm{~m}$ in diameter driven piles, three $1.0 \mathrm{~m}$ and $1.2 \mathrm{~m}$ in diameter prebored driven piles, as well as twenty $0.8 \mathrm{~m}-1.2 \mathrm{~m}$ in diameter bored piles in eleven project locations were considered.

In the examination process, the pile was modelled as a series of beam elements, while the surrounding soil was modelled as a series of linear elastic springs. The moduli were varied according to the distribution of $\mathrm{N}-\mathrm{SPT}$ values recorded in the associated deep boring data. In each load cycle, trial and error process were conducted to match the resulting pile head lateral deflection to the measured value.

The correlation in general tended to decrease as the lateral deflection increased. The results of regression analysis indicated relatively good correlations. The correlation for $0.45 \mathrm{~m}$ and $0.50 \mathrm{~m}$ in diameter driven piles appear to be the highest, followed by that for $0.8 \mathrm{~m}-1.2 \mathrm{~m}$ in diameter bored piles and that for $1.0 \mathrm{~m}$ and $1.2 \mathrm{~m}$ in diameter pre-bored driven piles. However, for pre-bored driven piles and bored piles with comparable diameters at relatively large lateral deflection, the correlation is about the same. All these indicate the influence of construction methods (driven piles versus pre-bored driven and bored piles) on the correlations defined in this study.

The authors gratefully acknowledge the part support provided through the research grant PUPT by Minister of Research, Technology, and Higher Education through Universitas Indonesia under the contract No 513/UN2.R3.1/HKP.05.00/2018. 


\section{References}

1. Murthy, V. Advanced Foundation Engineering. New Delhi: CBS Publishers and Distributors. (2007)

2. ASTM D3996: Standard Test Method for Lateral for Piles under Lateral Loads. ASTM (2007)

3. Reese, L. C., \& Impe, W. F. Single Piles and Pile Group under Lateral Loading 2nd Edition. Boca Raton: CNC Press. (2011)

4. E.Bowles, J. (1996). Foundation Analysis and Design. Singapore: The McGraw-Hill Companies, Inc. (1996)

5. OCDI. Technical Standards and Commentaries for Port and Harbour Facilities in Japan. (2002).

6. Coduto, D. P. Foundation Design 2nd Edition: Principles and Practices. New Jersey: Prentice- Hall. Inc. (2001) 